\title{
Dynamic Analysis of Ocular Fundus Changes after Different Doses of Bevacizumab in the Treatment of Retinopathy of Prematurity in Threshold Period
}

\section{Feng Chen ( $\nabla$ eyeguangzhou@126.com ) https://orcid.org/0000-0002-0362-7242 \\ Ying Yu \\ Guangzhou Women and Children's Medical Center \\ Jianxun Wang \\ Guangzhou Women and Children's Medical Center \\ Tian Liu \\ Guangzhou Women and Children's Medical Center \\ Daoman Xiang}

Guangzhou Children's Hospital: Guangzhou Women and Children's Medical Center

Guangzhou Women and Children's Medical Center

\section{Research Article}

Keywords: Retinopathy of prematurity, threshold period, vitreous injection, bevacizumab, fundus examination

Posted Date: April 28th, 2021

DOI: https://doi.org/10.21203/rs.3.rs-430209/v1

License: (c) (i) This work is licensed under a Creative Commons Attribution 4.0 International License. Read Full License 


\section{Abstract}

Purpose: To analyze the efficacy of three different doses of bevacizumab treatment on Threshold retinopathy of prematurity during different periods .

Methods: 36 cases (72 eyes) of infants with threshold ROP were analyzed, whom were treated with intravitreal injection of $1.25 \mathrm{mg}, 0.75 \mathrm{mg}$ or $0.5 \mathrm{mg}$ bevacizumab respectively from October $1^{\text {st }}, 2016$ to September $30^{\text {th }}, 2017$. After treatment, fundus examination results during five time points were recorded and classified into four grades according to the efficacy.

Results: There were significant differences in the changes of fundus among the 3 groups on the $4^{\text {th }}$ day and the $2^{\text {nd }}$ week after treatment $\otimes P<0.001 \otimes$. In the $1.25 \mathrm{mg}$ group, there was a significant difference in the changes of fundus on the $4^{\text {th }}$ day after treatment VS. the $2^{\text {nd }}$ week after treatment $(P<0.001)$. In the $0.5 \mathrm{mg}$ and $0.75 \mathrm{mg}$ group respectively, the changes of fundus were significantly different between each consecutive time points of the $4^{\text {th }}$ day, $2^{\text {nd }}$ week, $4^{\text {th }}$ week and $2^{\text {nd }}$ month after treatment $(P<0.001, P<0.001, P=0.01 ; P<0.001, P=0.01, P=0.032)$. The proportion of normal retinal vessels of the three groups is $41.67 \%-66.67 \%$ in the 3 rd month after treatment.

Conclusion: Among the three doses of bevacizumab treatment, the efficacy of $1.25 \mathrm{mg}$ group is the best on the $4^{\text {th }}$ day and the $2^{\text {nd }}$ week after treatment, and there was no difference after 4 weeks. The efficacy of $0.5 \mathrm{mg}$ and $0.75 \mathrm{mg}$ group changed significantly from the $4^{\text {th }}$ day to the $2^{\text {nd }}$ month after treatment. Longterm follow-up of fundus changes was still needed to avoid recurrence of ROP whatever the dose of bevacizumab was uesed.

\section{Introduction}

Retinopathy of prematurity (ROP) is characterized by the abnormal development and proliferation of immature retinal vessels, which is one of the main causes of blindness in premature infants. It is often found in preterm infants with low gestational age and low birth weight. For the infants with the risk of developing ROP, ophthalmologists should carry out routine fundus examination, early diagnosis and early treatment [1]. At present, retinal photocoagulation and intravitreal injection of anti-VEGF drugs are the main surgical methods for zone I or II ROP such as APROP, pre-threshold or early threshold ROP. Comparing with the traditional surgical treatment, intravitreal injection of anti-VEGF comprises the advantages of less operation time, less risk to damage visual field or develop high myopia caused by the destruction of peripheral retinal structure, less and delayed recurrence of ROP, and continued normal vascularization of peripheral retina. The commonly used anti-VEGF drugs include bevacizumab and ranibizumab.

At present, there is no unified standard for the use of bevacizumab in the treatment of ROP worldwide. The injection dose could be $0.025 \mathrm{ml}(0.625 \mathrm{mg}), 0.03 \mathrm{ml}(0.75 \mathrm{mg})$ or $0.05 \mathrm{ml}(1.25 \mathrm{mg})$, etc., or even less, in once or multiple times of treatment [2]. Clinical studies have found that several doses of bevacizumab treatment have achieved positive results in the treatment of threshold ROP, but the peripheral retina may not continue 
to vascularize or ROP recurrence may occur after the treatment. Therefore, it is recommended to closely follow up the fundus changes and perform surgical treatment if necessary [3-5].

However, there are no relevant reports on the efficacy, peripheral retinal vascularization cycle and recurrence rate of ROP after different doses of bevacizumab, which makes it impossible to provide a unified standard for the optimal effective dose of bevacizumab treatment and follow-up schedule for threshold ROP. Therefore, in this study, we aimed to assess the efficacy of three different commonly used doses of Bevacizumab intravitreal injection $(1.25 \mathrm{mg}, 0.75 \mathrm{mg}, 0.5 \mathrm{mg})$ on patients with threshold ROP

\section{Methods}

\section{Study cohort}

This is a retrospective study enrolling 36 infants (72 eyes) with threshold ROP diagnosed in our hospital from October 1st, 2016 to September 30th, 2017, including 27 males and 9 females. The gestational age was 26-34 weeks, with an average of $(29.19 \pm 1.95)$ weeks; the birth weight was $0.75-1.96 \mathrm{~kg}$, with an average of $(1.23 \pm 0.28) \mathrm{kg}$. Preterm infants with unstable vital signs during treatment or requiring additional retinal photocoagulation would be excluded from this study.

\section{Examination And Treatment}

Before treatment, the patients were dilated pupil and examined with RetCam $₫$ (Massie Laboratory, U.S.), a pediatric wide-range digital fundus imaging system. The examination results were interpreted by two different senior pediatric fundus doctors. The patients whom were diagnosed with threshold ROP were divided into three groups and treated with intravitreal injection of $0.03 \mathrm{ml}(0.75 \mathrm{mg}), 0.02 \mathrm{ml}(0.5 \mathrm{mg})$ and $0.05 \mathrm{ml}(1.25 \mathrm{mg})$ bevacizumab respectively. During the treatment, ECG monitoring and the assistance of nurses and anesthesiologists were provided. The basic steps are as follows: 1. Anesthesia of conjunctiva with $0.5 \%$ procaine eye drops 5 minutes before the operation; 2 . Routine local disinfection of the treated eye; 3 . Opening the eyelids of the treated eye with the special pediatric eyelid opener; 4 . Gently clamp the corneoscleral margin of the treated eye with ophthalmic forceps to fully expose the injection area. The needle was inserted at $1.5 \mathrm{~mm}$ from the corneoscleral margin and observed through the dilated pupil, that whether the needle has entered the center of the vitreous cavity. Different dosage of bevacizumab solution (Roche Group, U.S.) was injected slowly. After the injection, the needle was slowly withdrawn, and the injection port was pressed with a cotton swab until the bleeding was stopped and no liquid outflow was observed. In the end, the conjunctival sac was coated with TobraDex eye ointment, and the treated eye was covered with a small gauze.

\section{Follow-up}


The patients were reexamined with RetCam $\otimes$ on 4 days, 2 weeks, 4 weeks, 2 months and 3 months after treatment. The results were recorded. The main outcomes were evaluated according to the CRYO-ROP and ETROP study [6-7]. (1) According to the changes of fundus (curative efficacy), all cases could be described in four grades: Grade I, improvement - the regression of retinopathy and plus disease; Grade II, significant improvement -- the regression of retinopathy and the disappearance of plus disease; Grade III, cure -- the disappearance of retinopathy and plus disease; Grade IV, retinal vascularization -- disappearance of retinopathy and plus disease, with vascularization of peripheral retinal. (2) Definition of recurrent ROP: The retinopathy that did not regress or got even worse, with retinal neovascularization or bleeding.

\section{Data analysis}

SPSS 23.0 statistical software was applied to analyze the data. The fundus examination results on 4 days, 2 weeks, 4 weeks, 2 months and 3 months after treatment were recorded and analyzed using chi-square test.

\section{Results}

Results showed no significant difference in gestational age, birth weight or corrected gestational age among the three groups (Table 1). In 1.25mg group, 75\% (18 / 24) cases were in grade II, 8.33\% (2 / 24) cases were in grade I and $16.67 \%$ ( 4 / 24) cases were in grade III on the 4th day after treatment. With the extension of follow-up interval, 33.33\% (8 / 24) cases ended in grade III and 66.67\% (16 / 24) cases ended in grade IV on the 3rd month after treatment,In 0.5mg group, 58.33\% (14 / 24) cases were in grade I and $41.67 \%$ (10 / 24) cases were in grade II on the 4th day after treatment. With the extension of follow-up interval, 50\% (12 / 24) cases ended in grade III and 50\% (12 / 24) cases ended in grade IV on the 3rd month after treatment $\square$ In $0.75 \mathrm{mg}$ group, 50\% (12 / 24) cases were in grade I and 50\% (12/24) cases were in grade II on the 4th day after treatment. On the 4th week after treatment, one of the patients was found to have recurrent retinopathy and received laser photocoagulation. On the 3rd month after treatment, 54.17\% (13 / 24) cases ended in grade III and 41.67\% (10 / 24) cases ended in grade IV.

Table 1

Comparison of gestational weeks, birth weight and corrected gestational age at treatment among different doses of bevacizumab groups

\begin{tabular}{|c|c|c|c|c|}
\hline & $\begin{array}{l}1.25 \mathrm{mg} \\
\text { Bevacizumab }\end{array}$ & $\begin{array}{l}0.75 \mathrm{mg} \\
\text { Bevacizumab }\end{array}$ & $\begin{array}{l}0.5 \mathrm{mg} \\
\text { Bevacizumab }\end{array}$ & $\mathbf{P}$ \\
\hline Gestational weeks (weeks) & $29.38 \pm 1.89$ & $29.09 \pm 2.44$ & $29.11 \pm 1.60$ & 0.927 \\
\hline Weight (kg) & $1.30 \pm 0.34$ & $1.26 \pm 0.25$ & $1.13 \pm 0.23$ & 0.334 \\
\hline $\begin{array}{l}\text { Corrected gestational age at } \\
\text { treatment (weeks) }\end{array}$ & $36.40 \pm 2.52$ & $36.33 \pm 2.79$ & $38.30 \pm 1.61$ & 0.084 \\
\hline$\star P<0.05$ & & & & \\
\hline
\end{tabular}

Comparing among the three doses of bevacizumab treatment, there were both significant differences in the efficacy on the 4 th day and 2 nd week after treatment $(P<0.001, P<0.001)$. But there was no significant 
difference on the 4th week, 2nd month and 3rd month $(P=0.546,0.696, P=0.696)$ (Table 2). In 1.25mg group, there was a statistical difference $(P<0.001)$ on the 4 th day after treatment comparing with the 2nd week after treatment. However, there was no statistical difference comparing among other time points;in $0.5 \mathrm{mg}$ group, there were statistical differences between two consecutive time points on the 4 th day, $2 \mathrm{nd}$ week, 4th week and 2nd month after treatment $(P<0.001, P<0.001, P=0.01)$. However, there was no significant difference on the 2 nd month VS. 3rd month $(P=0.077)$ (Table 3$)$. In $0.75 \mathrm{mg}$ group, there were statistical differences between two consecutive time points on the 4th day, 2nd week, 4th week and 2nd month after treatment $(P<0.001, P=0.01, P=0.032)$. However, there was no significant difference on the 2nd month VS. 3rd month $(P=0.55)$ (Table 3$)$.

Table 2

Comparison of fundus changes (curative efficacy) among different doses of bevacizumab groups during different periods after treatment

\begin{tabular}{|c|c|c|c|c|c|c|c|}
\hline & \multirow{2}{*}{$\begin{array}{l}\text { Bevacizumab } \\
\text { dosage }\end{array}$} & \multicolumn{6}{|c|}{ Fundus changes } \\
\hline & & Improvement & $\begin{array}{l}\text { Significant } \\
\text { improvement }\end{array}$ & Cure & $\begin{array}{l}\text { Retinal } \\
\text { vascularization }\end{array}$ & $\chi^{2}$ & $P$ \\
\hline \multirow{3}{*}{$\begin{array}{l}\text { The } \\
\text { 4th } \\
\text { day }\end{array}$} & $1.25 \mathrm{mg}$ & 2 & 18 & 4 & 0 & \multirow[t]{3}{*}{17.873} & \multirow[t]{3}{*}{$0^{*}$} \\
\hline & $0.5 \mathrm{mg}$ & 14 & 10 & 0 & 0 & & \\
\hline & $0.75 \mathrm{mg}$ & 12 & 12 & 0 & 0 & & \\
\hline \multirow{3}{*}{$\begin{array}{l}\text { The } \\
\text { 2nd } \\
\text { week }\end{array}$} & $1.25 \mathrm{mg}$ & 0 & 0 & 24 & 0 & \multirow[t]{3}{*}{19.910} & \multirow[t]{3}{*}{0 * } \\
\hline & $0.5 \mathrm{mg}$ & 0 & 14 & 10 & 0 & & \\
\hline & $0.75 \mathrm{mg}$ & 2 & 10 & 12 & 0 & & \\
\hline \multirow{3}{*}{$\begin{array}{l}\text { The } \\
\text { 4th } \\
\text { week }\end{array}$} & $1.25 \mathrm{mg}$ & 0 & 0 & 22 & 2 & \multirow[t]{3}{*}{1.212} & \multirow[t]{3}{*}{0.546} \\
\hline & $0.5 \mathrm{mg}$ & 0 & 0 & 24 & 0 & & \\
\hline & $0.75 \mathrm{mg}$ & 0 & 5 & 14 & 4 & & \\
\hline \multirow{3}{*}{$\begin{array}{l}\text { The } \\
\text { 2nd } \\
\text { month }\end{array}$} & $1.25 \mathrm{mg}$ & 0 & 0 & 18 & 6 & \multirow[t]{3}{*}{0.725} & \multirow[t]{3}{*}{0.696} \\
\hline & $0.5 \mathrm{mg}$ & 0 & 0 & 18 & 6 & & \\
\hline & $0.75 \mathrm{mg}$ & 0 & 0 & 15 & 8 & & \\
\hline \multirow{3}{*}{$\begin{array}{l}\text { The } \\
\text { 3rd } \\
\text { month }\end{array}$} & $1.25 \mathrm{mg}$ & 0 & 0 & 8 & 16 & \multirow[t]{3}{*}{2.681} & \multirow[t]{3}{*}{0.262} \\
\hline & $0.5 \mathrm{mg}$ & 0 & 0 & 12 & 12 & & \\
\hline & $0.75 \mathrm{mg}$ & 0 & 0 & 13 & 10 & & \\
\hline
\end{tabular}


Table 3

Comparison of fundus changes (efficacy) among different periods after treatment in three doses of bevacizumab groups

\begin{tabular}{|c|c|c|c|c|c|c|}
\hline & \multicolumn{2}{|l|}{$1.25 \mathrm{mg}$} & \multicolumn{2}{|l|}{$0.5 \mathrm{mg}$} & \multicolumn{2}{|l|}{$0.75 \mathrm{mg}$} \\
\hline & $x^{2}$ & $\mathbf{P}$ & $x^{2}$ & $\mathbf{P}$ & $x^{2}$ & $\mathbf{P}$ \\
\hline The 4th day VS. The 2nd week & 32.696 & $0 *$ & 24.011 & $0^{*}$ & 18.148 & $0^{*}$ \\
\hline The 2nd week VS. The 4th week & 2.043 & 0.153 & 19.353 & $0^{*}$ & 6.499 & $0.011^{*}$ \\
\hline The 4 th week VS. The 2nd month & 2.350 & 0.125 & 6.714 & $0.01 *$ & 4.605 & $0.032^{\star}$ \\
\hline The 2nd month VS The 3rd month & 8.217 & $0.004^{*}$ & 3.133 & 0.077 & 0.357 & 0.55 \\
\hline
\end{tabular}

\section{Discussion}

Nowadays, the efficacy of anti-VEGF treatment on ROP has been confirmed in many aspects. Bevacizumab and ranibizumab are the most commonly used anti-VEGF drugs in clinic. The latter may have less systemic effects than the former, because it has a shorter half-life in the blood. It was found that after intravitreal injection of ranibizumab, plasma VEGF levels decreased the next day, but returned to normal after one week [8]. In another study, it was found that the recurrence rate of ROP patients treated with the first injection of ranibizumab may be higher, because it could vanish from the ocular local more quickly [9]. A large study [10] showed that 127 eyes (45\%) of 283 eyes relapsed after intravitreal injection of ranibizumab. For these reasons, we chose bevacizumab, which is also the most commonly used antiVEGF drug for ROP in the world.

Results in our study showed that the cure rates of $1.25 \mathrm{mg}, 0.5 \mathrm{mg}$ and $0.75 \mathrm{mg}$ bevacizumab treatment were $100 \%, 100 \%$ and $95.83 \%$ respectively in the 2 nd month after treatment. And the normal retinal vascularization rate of the three groups was only $41.67 \%-66.67 \%$. In comparison, Henaine-Berra A. et al. studied 47 eyes of 26 patients with threshold or pre-threshold ROP treated with $0.75 \mathrm{mg}$ bevacizumab, with regular fundus fluorescein photography and Retcam examination, and found that the cure rate was $92 \%$, with $45 \%$ of the patients did not complete normal retinal vascularization. However, Wu W.C. et al. conducted a multicenter study in Taiwan, and found that the cure rate of patients with stage 3 ROP treated with once $0.625 \mathrm{mg}$ bevacizumab was $90 \%$, with $10 \%$ of the cases needed additional laser treatment [12]. The above reports are similar to the experimental results of $0.5 \mathrm{mg}$ and $0.75 \mathrm{mg}$ groups in our study, suggesting that regular review is still needed after bevacizumab treatment to prevent recurrence.

Considering the potential effects of anti-VEGF drugs on the organs of the whole body, experts have been trying to use low-dose bevacizumab to treat ROP. Wallace et al. [13] used intravitreal injection of $0.25 \mathrm{mg}$, $0.125 \mathrm{mg}, 0.063 \mathrm{mg}$ or $0.031 \mathrm{mg}$ bevacizumab in 61 eyes with type I ROP in a single-blinded multicenter study. They found that low-dose bevacizumab treatment has positive effects, but many eyes needed additional treatment. Dikci S. et al. Also confirmed the above results in a clinical study of $0.5 \mathrm{mg}$ and 
$0.625 \mathrm{mg}$ bevacizumab in the treatment of acute posterior pole retinopathy of prematurity (AP-ROP), in which the recurrence rate of the $0.5 \mathrm{mg}$ group was higher, and half of the eyes needed further photocoagulation at the corrected gestational age of $47.6 \pm 1.5$ weeks [14]. In the $0.5 \mathrm{mg}$ group of our study, the cure rate was $100 \%$ and the retinal vascularization rate was $50 \%$ on 3 months after treatment (corrected gestational age 49-50 weeks), with no recurrent cases. Considering the limited number of cases and insufficient follow-up time, further study is still needed. However, based on the current literature reports, we believe that ROP treated with ultra-low dose bevacizumab is more likely to recur.

For the postoperative evaluation of bevacizumab-treated ROP, fundus examination should be carried out regularly. The wide-angle digital fundus photography system (RetCam) and fluorescein angiography can be used to evaluate and analyze [15-16]. Because the latter requires intravenous injection of fluorescein sodium contrast agent, there is a certain risk for the infants, so it is not recommended to be used repeatedly. Therefore, at present, we mainly use fundus photography equipment such as RetCam for examination. Our study showed that the curative efficacy of bevacizumab treatment was different under different doses or under different periods. On the 4th day and 2nd week after treatment, the curative efficacy of $1.25 \mathrm{mg}$ group was better, and there was no difference among the three groups after 4 weeks. The efficacy of $0.5 \mathrm{mg}$ and $0.75 \mathrm{mg}$ groups changed significantly from the 4 th day to 2 nd month after treatment, with normal retinal vascularization rate of the three groups being only $41.67 \%-66.67 \%$. The results also showed that the efficacy of bevacizumab in the ultra-routine dose group was better than that in the routine dose group within 2 weeks after treatment, and the efficacy was similar to that in the routine dose group and the low-dose group within 1 month after treatment, whereas the efficacy of bevacizumab in the latter two groups became gradually obvious with the extension of postoperative time (within 3 months). We believe it should not be simply deducted that the efficacy of low-dose bevacizumab is not obvious, since the degradation degree of different groups variated significantly in the first two weeks after treatment. Long-term postoperative fundus review and dynamic observation are needed. As long as the no deterioration of retinopathy was observed after treatment, additional therapy is not necessary. Up till now, there is no related research report.

In terms of disease recurrence, multiple studies have found that comparing with photocoagulation, the average recurrence time of retinopathy treated with intravitreal injection of bevacizumab is about 10 weeks later. Therefore, it is suggested that for the treatment of ROP with intravitreal bevacizumab, the follow-up time should be longer, so as to detect the recurrence of the disease [17-18]. The three groups of patients in this study were all nonlocal and could not adhere to the long-term follow-up, so they only followed up to the 3rd month after treatment, and then followed up in the local hospital. In the $0.75 \mathrm{mg}$ group, one patient was found to have a recurrence of ROP in the left eye 4 weeks after treatment, and laser treatment was given. No recurrence was found in other cases. Because the pharmacokinetic duration of bevacizumab in newborns may be longer than that in adults, the efficacy, recurrence rate and safety of bevacizumab may be different. At the same time, the blood-retinal barrier of ROP infants is not fully developed. Therefore, the results of bevacizumab injection in preterm infants are different from that of adults. Intraocular injection of bevacizumab in preterm infants had been proven to reduce serum VEGF level [19]. whereas, many organs of ROP infants are not fully developed. The decrease of VEGF concentration in blood may affect 
the develop of nervous system, kidney, lung and other related organs. Arima M. et al. [20] conducted a 10year retrospective study, and used the Kyoto Scale of Psychological Development (KSPD) to evaluate the neurodevelopment of type I ROP patients treated with early use of $0.625 \mathrm{mg}$ bevacizumab injection at the age of 18 months. The results showed that the treatment may lead to the impairment of interpersonal relationship, social communication and / or speech ability development in premature infants. Therefore, we suggest that low-dose bevacizumab should be used in the treatment of ROP.

Summary: $\otimes$ Comparing the three doses of bevacizumab treatment, the efficacy of $1.25 \mathrm{mg}$ group is the best on the 4th day and the $2 \mathrm{nd}$ week after treatment, and there is no difference among the three groups after 4 weeks. The efficacy of $0.5 \mathrm{mg}$ and $0.75 \mathrm{mg}$ group changes significantly from the 4 th day to the $2 \mathrm{nd}$ month after treatment, which needs to be followed up regularly and timely to assess the situation of fundus after treatment. $\otimes$ The proportion of normal retinal vessels of the three groups is $41.67 \%-66.67 \%$ in the 3rd month after treatment. Long-term follow-up of fundus changes is still needed to avoid recurrence of ROP whatever the dose of bevacizumab is uesed for treatment of ROP. $\triangle$ This study is limited in the number of subjects and follow-up length, also in lack of multi center data, which requires further study.

\section{Declarations}

Funding The study was funded by The Guangzhou Medical and health science and technology project in 2016『No. 20161a010034区.

Conflicts of interest None of the authors have any proprietary interest in any material mentioned. The authors declare that there is no conflict of interest regarding the publication of this paper.

Authors' contributions All authors contributed to the study conception and design. Material preparation, data collection and analysis were performed by Jianxun Wang, Tian Liu and Ying Yu. The first draft of the manuscript was written by Feng Chen and Daoman Xiang. All authors commented on previous versions of the manuscript. All authors read and approved the final manuscript.

Ethics approval/Consent for publication This study was approved by the ethic committee of scientific research of Guangzhou Women and Children's Medical Center before the implementation of the project. The informed consents of the parents of the enrolled infants were obtained before the treatment.

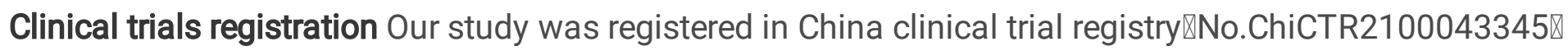

\section{References}

1. Foroozan R, Connolly BP, Tasnan WS (2001) Outcomes after laser thempyfor threshold retinopathy of prematurity. OphthMmolosy 108(9):1644-1646

2. Mintz-Hittner HA, Kennedy KA, Chuang AZ, BEAT-ROP Cooperative Group (2011) Efficacy of intravitreal bevacizumab for stage $3+$ retinopathy of prematurity. N Engl J Med 364(7):603-615 
3. Ekinci DY, Vural AD, Bayramoglu SE, Onur IU, Hergunsel GO (2019) Assessment of vascular leakage and its development with FFA among patients treated with intravitreal anti-VEGF due to aggressive posterior ROP. Int Ophthalmol 39(12):2697-2705

4. Mansukhani SA, Hutchinson AK, Neustein R, Schertzer J, Allen JC, Hubbard GB (2019) Fluorescein Angiography in Retinopathy of Prematurity: Comparison of Infants Treated with Bevacizumab to Those with Spontaneous Regression. Ophthalmol Retina 3(5):436-443

5. Chang YS, Chen YT, Lai TT, Chou HC, Chen CY, Hsieh WS, Yang CM, Yeh PT, Tsao PN (2019) Involution of retinopathy of prematurity and neurodevelopmental outcomes after intravitreal bevacizumab treatment. PLoS One 14(10):e0223972

6. Cryotherapy for Retinopathy of Prematurity Cooperative Group (1988) Multicenter trial of cryotherapy for retinopathy of prematurity: preliminary results. Arch Ophthalmol 106:471-479

7. Early Treatment for Retinopathy of Prematurity Cooperative Group (2003) Revised indications for the treatment of retinopathy of prematurity: results of the Early Treatment for Retinopathy of Prematurity randomized trial. Arch Ophthalmol 121:1684-1694

8. Zhou Y, Jiang Y, Bai Y, Wen J, Chen L (2016) Vascular endothelial growth factor plasma levels before and after treatment of retinopathy of prematurity with ranibizumab. Graefes Arch Clin Exp Ophthalmol 254:31-36

9. Stahl A, Krohne TU, Eter N, Oberacher-Velten I, Guthoff R, Meltendorf S, Ehrt O, Aisenbrey S, Roider J, Gerding $\mathrm{H}$ (2018) Comparing alternative ranibizumab dosages for safety and effificacy in retinopathy of prematurity: A randomized clinical trial. JAMA Pediatr 172:278-286

10. Huang Q, Zhang Q, Fei P, Xu Y, Lyu J, Ji X, Peng J, Li YA, Zhao P (2017) Ranibizumab injection as primary treatment in patients with retinopathy of prematurity: anatomic outcomes and inflfluencing factors. Ophthalmology 124(8):1156-1164

11. Henaine-Berra A, Garcia-Aguirre G, Quiroz-Mercado H (2014) Retinal fluorescein angiographic changes following intravitreal anti-VEGF therapy. J AAPOS 18(2):120-123

12. Wu WC, Yeh PT, Chen SN, Yang CM, Lai CC, Kuo HK (2011) Effects and complications of bevacizumab use in patients with retinopathy of prematurity: a multicenter study in taiwan. Ophthalmology 118(1):176-183

13. Wallace DK, Dean TW, Hartnett ME, Kong L, Smith LE, Hubbard GB, McGregor ML, Jordan CO, Mantagos IS, Bell EF, Kraker RT (2018) Pediatric Eye Disease Investigator Group. A Dosing Study of Bevacizumab for Retinopathy of Prematurity: Late Recurrences and Additional Treatments. Ophthalmology 125(12):1961-1966

14. Dikci S, Ceylan OM, Demirel S, Yılmaz T (2018) Which dose of bevacizumab is more effective for the treatment of aggressive posterior retinopathy of prematurity: lower or higher dose? Arq Bras Oftalmol 81(1):12-17

15. Chen TA, Shields RA, Bodnar ZH, Callaway NF, Schachar IH, Moshfeghi DM (2019) A Spectrum of Regression Following Intravitreal Bevacizumab in Retinopathy of Prematurity. Am J Ophthalmol 198:63-69 
16. Toy BC, Schachar IH, Tan GS, Moshfeghi DM (2016) Chronic Vascular Arrest as a Predictor of Bevacizumab Treatment Failure in Retinopathy of Prematurity. Ophthalmology 123(10):2166-2175

17. Miyake T, Sawada O, Kakinoki M, Sawada T, Kawamura H, Ogasawara K, Ohji M (2010) Pharmacokinetics of bevacizumab and its effect on vascular endothelial growth factor after intravitreal injection of bevacizumab in macaque eyes. Invest Ophthalmol Vis Sci 51(3):1606-1608

18. Martínez-Castellanos MA, González-H León A, Romo-Aguas JC, Gonzalez-Gonzalez LA (2020) A proposal of an algorithm for the diagnosis and treatment of recurrence or treatment failure of retinopathy of prematurity after anti-VEGF therapy based on a large case series. Graefes Arch Clin Exp Ophthalmol 258(4):767-772

19. Hoerster R, Muether P, Dahlke C, Mehler K, Oberthür A, Kirchhof B, Fauser S (2013) Serum concentrations of vascular endothelial growth factor in an infant treated with ranibizumab for retinopathy of prematurity. Acta Ophthalmol 91(1):e74-e75

20. Arima M, Akiyama M, Fujiwara K, Mori Y, Inoue H, Seki E, Nakama T, Tsukamoto S, Ochiai M, Ohga S, Sonoda KH (2020) Neurodevelopmental outcomes following intravitreal bevacizumab injection in Japanese preterm infants with type 1 retinopathy of prematurity. PLoS One 20(3):0230678 15(

\section{Figures}

\section{5mg Bevacizumab group}
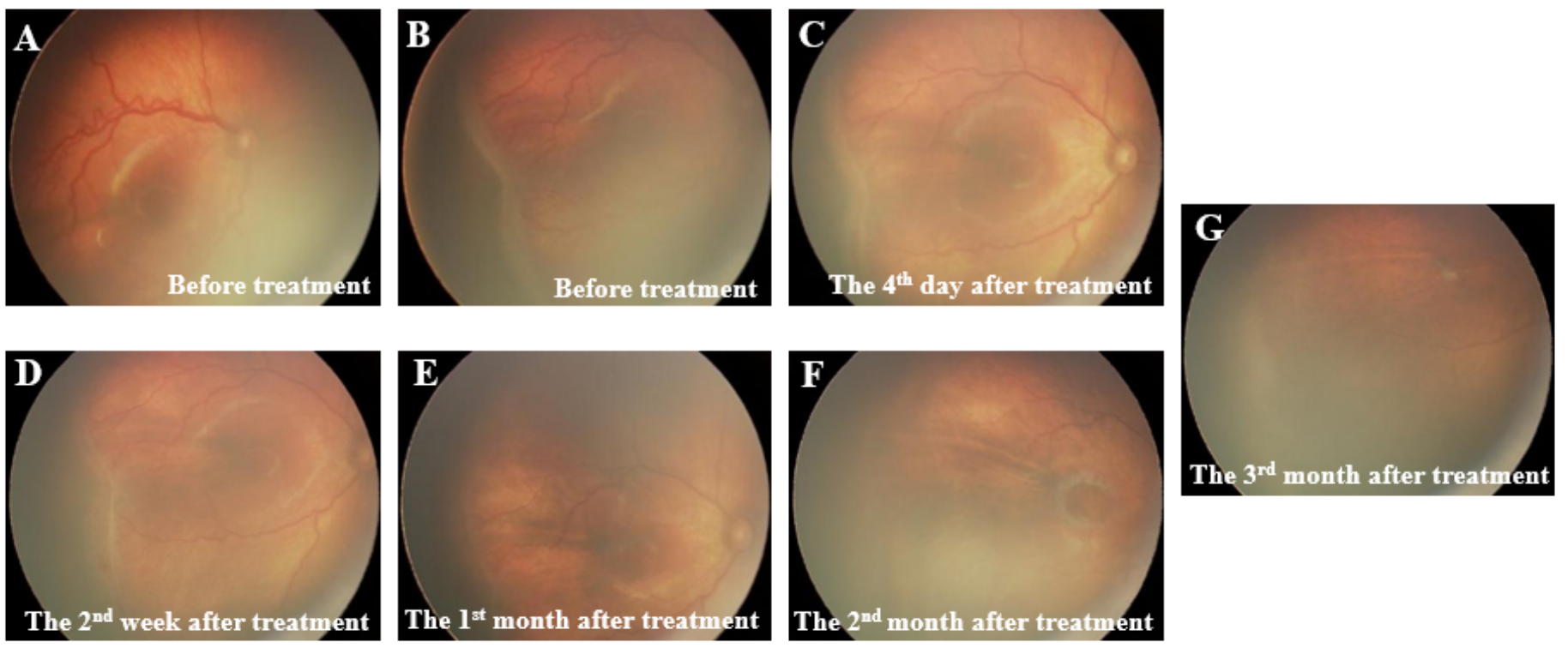

\section{Figure 1}

A preterm infant with gestational age of 26 weeks +5 days and birth weight of $750 \mathrm{~g}$, with corrected gestational age of 36 weeks +5 days, was diagnosed with bilateral zone II, stage $3+$ ROP. The $0.02 \mathrm{ml}(0.5$ $\mathrm{mg}$ ) bevacizumab was injected into the vitreous cavity of both eyes. Before treatment: (A-B)In the right eye, the thickening grayish white fibrous membrane proliferation was found in zone II of the temporal retina. A 
large gray avascular area was found in the peripheral retina. Central and branch vessels dilated tortuously (plus change). Fundus examination on the 4th day after treatment: (C) In the right eye, the proliferation of fiber membrane on the temporal retina was reduced comparing with that before treatment. And the plus disease was alleviated. (D) Two weeks after treatment, the temporal retinopathy of the right eye was further alleviated. However, there was still a large avascular area in the peripheral retina. (E) One month after treatment, the temporal retinopathy of the right eye showed "linear change", without plus disease. However, there was still a large avascular area in the peripheral retina. (F)Two months after treatment, the temporal retinopathy of the right eye completely disappeared, and the avascular area in the peripheral retina was shrunk, without plus disease. $(G)$ Three months after treatment, the peripheral retina of the right eye had been vascularized without any lesions or plus disease.

\section{$1.25 \mathrm{mg}$ Bevacizumab group}
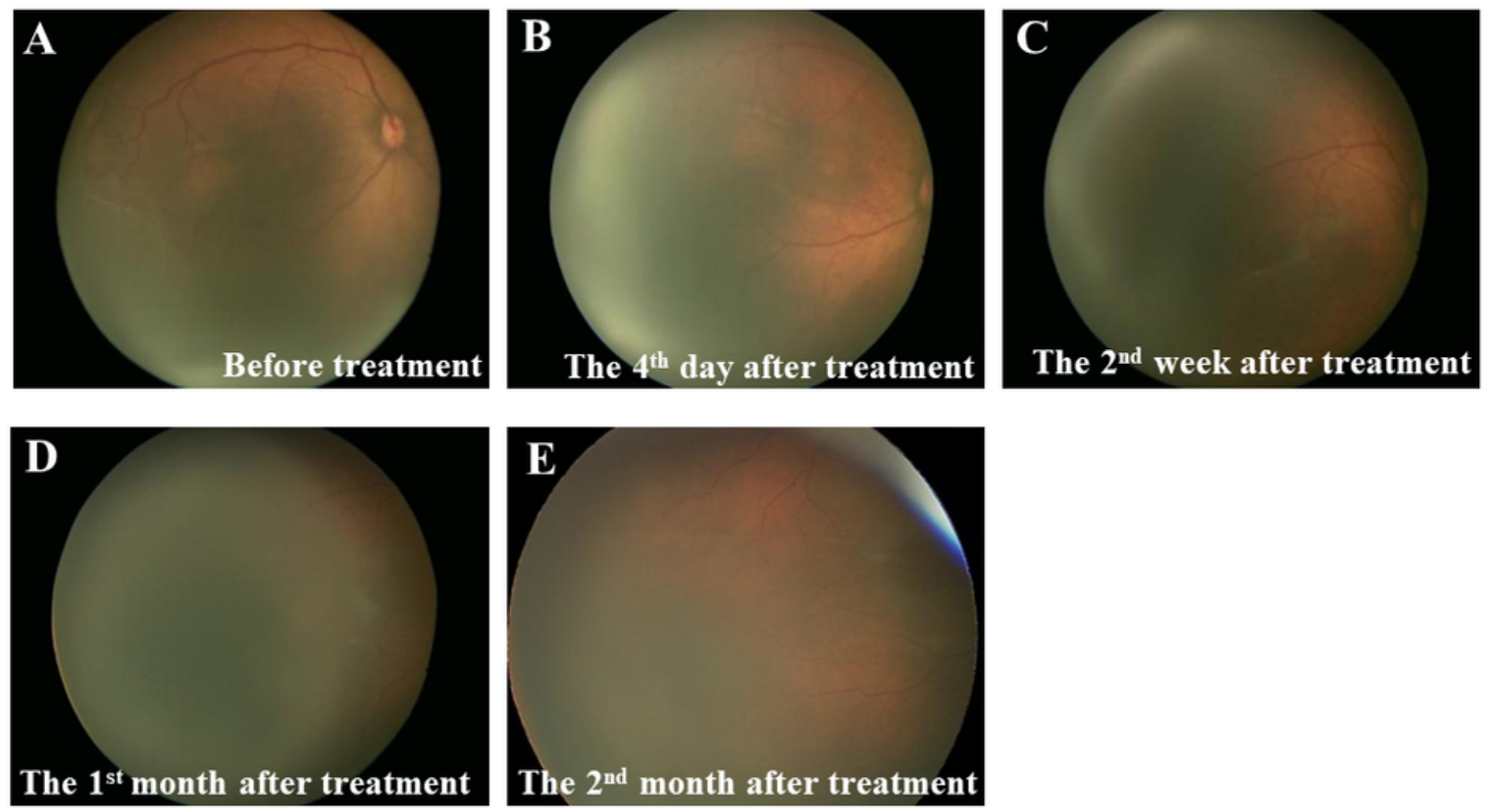

\section{Figure 2}

A preterm infant with 29 gestational weeks and birth weight of $1400 \mathrm{~g}$, with corrected gestational age of 41 weeks, was diagnosed with bilateral zone II stage $3+$ ROP. $0.05 \mathrm{ml}(1.25 \mathrm{mg})$ bevacizumab was injected into the vitreous cavity of both eyes. Before treatment: $(A)$ In the right eye, the proliferation of the thickening fibrous vascular membrane was found in the zone II of the temporal retina. And a large gray avascular area was found in the peripheral retina. The central and branch vessels dilated tortuously. Fundus examination on the 4th day after treatment:(B) In the right eye, the fibroproliferative lesions on the temporal retina have disappeared. A large avascular area was found in the peripheral retina, without plus disease. (C) Two weeks after treatment, the avascular area in the peripheral retina of the right eye was shrunk, without any lesions or plus disease. (D) One month after treatment, the avascular area in the peripheral retina of the right eye was further shrunk, without any lesion or plus disease. (E) Two months 
after treatment, the peripheral retina of the right eye had completed vascularized, without any lesions or plus disease.

\section{$0.75 \mathrm{mg}$ Bevacizumab group}
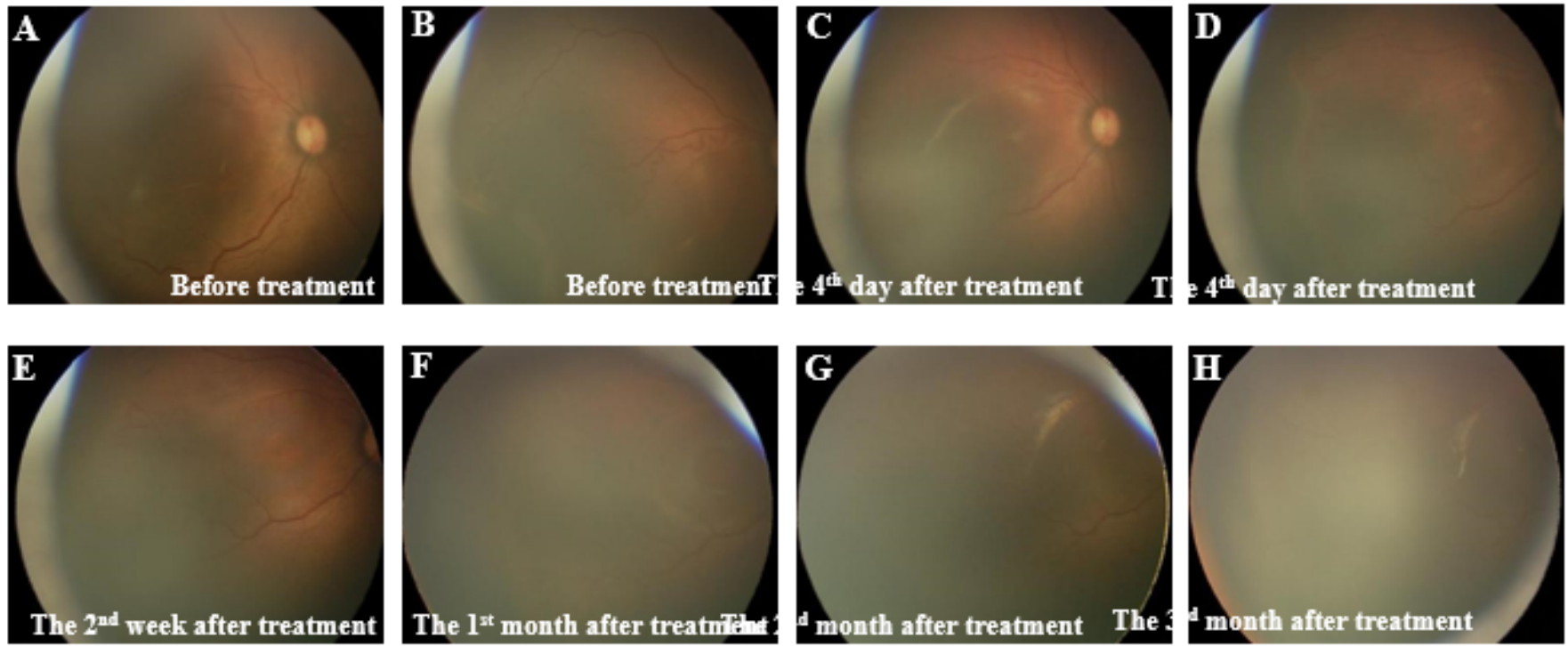

\section{Figure 3}

A preterm infant with gestational age of 27 weeks +1 day and birth weight of $1000 \mathrm{~g}$, with corrected gestational age of 34 weeks +3 days. The diagnosis before treatment: bilateral zone Il stage $3+$ ROP. $0.03 \mathrm{ml}(0.75 \mathrm{mg})$ bevacizumab was injected into the vitreous cavity of both eyes. Before treatment: (A-B) In the right eye, the thickening fibrous vascular membrane was found in zone II of the temporal retina of the right eye. A large gray avascular area was found in the peripheral retina. The central and branch vessels dilated tortuously (plus disease). Fundus examination on the 4th days after treatment: (C-D) The proliferation of retinal fibrovascular membrane and the plus disease in the temporal retina of the right eye were alleviated comparing with those before treatment. (E) On 2 weeks after treatment, the temporal retinopathy of the right eye was further alleviated, without plus disease. However, there was still a large avascular area in the peripheral retina. One month after treatment, the temporal retinopathy of the right eye showed "linear change", without plus change. There was still a large avascular area in the peripheral retina. Two months after treatment, the temporal retinopathy of the right eye completely disappeared. And the avascular area in the peripheral retina was shrunk, without plus disease. Three months after treatment, the temporal retinopathy of the right eye completely disappeared, and the peripheral retina was basically vascularized without plus disease. 